\title{
Article \\ Characterization of Saponins from Various Parts of Platycodon grandiflorum Using UPLC-QToF/MS
}

\author{
So-Jeong Lee (D), Heon-Woong Kim, Suji Lee, Ryeong Ha Kwon, Hyemin Na, Ju Hyung Kim, Chi-Do Wee, \\ Seon Mi Yoo and Sang Hoon Lee*
}

Citation: Lee, S.-J.; Kim, H.-W.; Lee, S.; Kwon, R.H.; Na, H.; Kim, J.H.; Wee, C.-D.; Yoo, S.M.; Lee, S.H Characterization of Saponins from Various Parts of Platycodon grandiflorum Using UPLC-QToF/MS. Molecules 2022, 27, 107. https:// doi.org/10.3390/molecules27010107

Academic Editor: Nuno Neng

Received: 29 November 2021

Accepted: 21 December 2021

Published: 24 December 2021

Publisher's Note: MDPI stays neutral with regard to jurisdictional claims in published maps and institutional affiliations.

Copyright: (C) 2021 by the authors. Licensee MDPI, Basel, Switzerland. This article is an open access article distributed under the terms and conditions of the Creative Commons Attribution (CC BY) license (https:// creativecommons.org/licenses/by/ $4.0 /)$.
Department of Agro-food Resources, National Institute of Agricultural Science, Rural Development Administration, Wanju-gun 55365, Jeollabuk-do, Korea; quizhalo@naver.com (S.-J.L.); ksharrier@korea.kr (H.-W.K.); sujiseven@naver.com (S.L.); haha9733@korea.kr (R.H.K.); na970713@naver.com (H.N.); ddong128@naver.com (J.H.K.); cdwee@korea.kr (C.-D.W.); yousm@korea.kr (S.M.Y.)

* Correspondence: spprigan@korea.kr; Tel.: +82-63-238-3562; Fax: +82-63-238-3841

Abstract: Platycodon grandiflorum (PG) is known as a high-potential material in terms of its biological activity. The objective of this report is to provide chromatographic and mass fragment ion data of 38 simultaneously identified saponins, including novel compounds, by analyzing them through ultra-performance liquid chromatography coupled with quadrupole time-of-flight mass spectrometry (UPLC-QToF/MS). In so doing, we investigated their diverse conditions, including morphological parts (stems, roots, buds, and leaves), peeling (or not), and blanching of PG. The total contents of individual saponins indicated an order of roots (containing peel, $1674.60 \mathrm{mg} / 100 \mathrm{~g}$, dry weight) > buds $(1364.05)>$ roots (without peel, 1058.83) $\approx$ blanched roots (without peel, 945.17) $\approx$ stems $(993.71) \approx$ leaves $(881.16)$. When considering three types of aglycone, the platycodigenin group (55.04 $\sim 68.34 \%$ ) accounted for the largest proportion of the total content, whereas the platycogenic acid A group accounted for $17.83 \sim 22.61 \%$, and the polygalacic acid group represented $12.06 \sim 22.35 \%$. As they are classified as major compounds, novel saponins might be utilized for their role in healthy food for human consumption. Additionally, during blanching, the core temperature of PG was satisfied with the optimal condition, thus activating the enzymes related to biotransformation. Furthermore, through the use of this comprehensive data, additional studies related to buds, as well as roots or the characterization of individual saponins, can be conducted in a rapid and achievable manner.

Keywords: Platycodon grandiflorum; saponin; UPLC-QTOF/MS

\section{Introduction}

Platycodon grandiflorum belongs to the Campanulaceae family, and it has been widely used as a traditional herb medicine to treat cough and sore throat; it has also been used as a food source, especially in northeast Asian countries, such as South Korea and China [1-6]. Raw PG roots are consumed in salads, whereas pickled fresh roots are used in juice, the traditional dish kimchi, jeonggwa, and as a functional food taken in pill form, or cooked by blanching or steaming $[1,7,8]$. Platycodi Radix (PR), i.e., the roots of PG, have reported biological properties, such as anti-inflammatory, antitumor, hepa protection, and antiobesity effects [9-14].

Plants synthesize different bioactive secondary metabolites such as saponins, alkaloids, flavonoids, terpenoids, and tannins. Among these, saponins, which are derived from 'sapo', a Latin word meaning 'soap', are largely subdivided into two classes: a triterpenoid (30 carbon atoms) and a steroid (27 carbon atoms). Additionally, based on the carbon of the aglycone, saponins are classified into 12 types, including dammaranes and oleananes [15-18]. Saponin derivatives are found in a large number of plants, such as Glycine max, Panax ginseng, Codonopsis lanceolata, Camellia sinensis, Puerariae lobata, and 
Centella asiatica, including Platycodon grandiflorum [19-23]. Previous reports show the total saponin content of Panax ginseng to be $57.2 \sim 121.8 \mathrm{mg} / \mathrm{g}$, dry weight (DW) [24,25]. Until recently, saponins of Platycodon grandiflorum have been reported to have biological activities related to anti-inflammation in certain respiratory diseases. These corresponding symptoms become influential by spreading coronavirus (COVID-19) around the world, a disease that can have a lethal effect on the respiratory system. Therefore, this study focuses on analyzing saponins in Platycodon grandiflorum to support follow-up studies.

Many previous studies reported the characterization of saponins from Platycodi Radix using HPLC (high performance liquid chromatography) [9,26-29]. In recent years, UPLC (ultra-performance liquid chromatography) coupled with MS (mass spectrometry) has shown itself to be an appropriate instrument to analyze various saponin derivatives [12,30-33]. Based on a previous study, the identification and quantification of analytes using an MRM (multiple reaction monitoring) mode has been implemented to achieve a higher sensitivity [34].

In terms of previous research, there has yet to be a report comprehensively describing the four different parts of the plant, including the stems, leaves, roots, and buds, as well as a description of the materials used for blanching. Even though other studies have been conducted with various parts of PG, no study has simultaneously analyzed 38 saponins using UPLC-QTOF-mass spectrometry $[4,14,32,35,36]$. Therefore, in this study, using UPLC combined with QTOF-mass spectrometry analysis, 38 saponins were identified or tentatively characterized with four different parts, including the blanching process. Thus, considering the change in saponin content in these materials, along with the transformation in their structure, platycodin (major saponin in PG) pathways are examined in light of previous studies [37-40].

\section{Results and Discussion}

\subsection{Identification of Saponins from P. grandiflorum}

In this study, the identification of saponin derivatives was compared with the nine correct standards by retention time (RT), whereas mass fragmentation was measured using the MRM (multiple reaction method). The standards were deapi-platycoside E, platycoside E, deapi-platycodin D3, platycodin D3, deapi-platycodin D (not detected in samples), platycodin D2, platycodin D, polygalacin D (not detected), and 2"-O-acetyl platyconic acid A, respectively, in the elution order of RT. As a result, peak 2, 3, 8, 10, 24, 25 , and 38 were confirmed accurately and identified as deapi-platycoside E, platycoside E, deapi-platycodin D3, platycodin D3, platycodin D2, platycodin D, and 2"-O-acetyl platyconic acid A, respectively. The remains of the peaks were identified by comparing the mass fragmentation and RT of the compounds in a previously constructed saponin library (Supplementary Materials; Table S1). A total of 38 saponin derivatives, including major saponins (platycodin D and platycodin E known as PG saponins), were identified from $P$. grandiflorum using ultra-performance liquid chromatography coupled with electrospray ionization tandem mass spectrometry (UPLC-ESI-MS) (Table S2).

\subsection{Quantification of Saponins from P. grandiflorum}

The contents of platycodin-related saponins in Platycodon grandiflorum were calculated using tubeimoside I (100 ppm) as an internal standard. The 38 saponins we identified were divided into three types in the aglycone group (Figure 1). Total saponin content is presented in Table 1, and the contents of the four parts ranged from $881.16 \pm 5.15$ to $1674.60 \pm 25.45 \mathrm{mg} / 100 \mathrm{~g}$ dry weight (DW) in Platycodon grandiflroum. The chromatograms of representative samples are presented in Figures 2 and 3. 


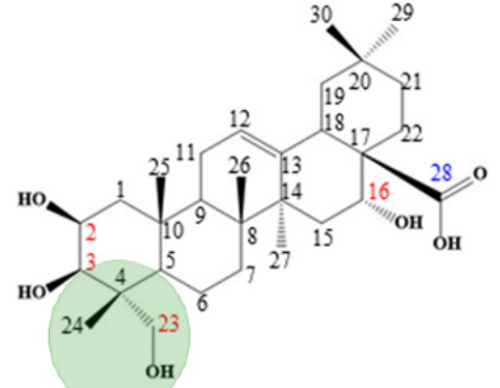

Polygalacic $\operatorname{acid}\left(\mathrm{m} / \mathrm{Z} 505,[\mathrm{M}+\mathrm{H}]^{+}\right)$ $[28,38,16 \alpha, 23 \alpha$-tetrahydroxy-olean-12ene-28-oic acid]

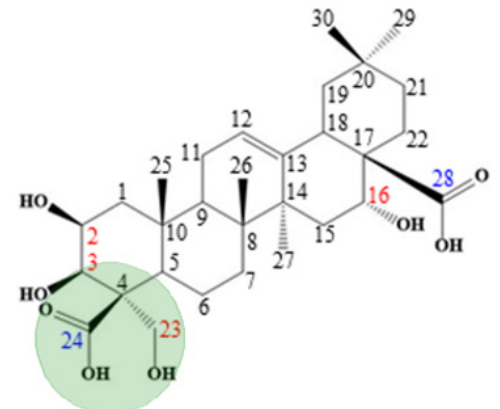

Platycogenic acid $\mathbf{A}(\mathrm{m} / \mathrm{z} 535$, $\left.[\mathrm{M}+\mathrm{H}]^{+}\right)$

$[26,36,16 \alpha, 23 \alpha$-tetrahydroxy-olean-12-ene24,28-dioic acid]

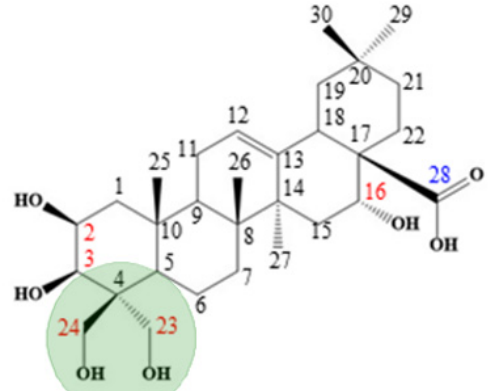

Platycodigenin $\left(m / 2521,[\mathrm{M}+\mathrm{H}]^{+}\right)$

$[28,38,16 \alpha, 23 \alpha, 248$-pentahydroxy-olean-12ene-28-oic acid]

Figure 1. Three types of aglycone groups (polygalacic acid, platycogenic acid A, platycodigenin).

The results of total saponin contents of the individual parts were in the following order: roots (containing peel, $1674.60 \mathrm{mg} / 100 \mathrm{~g}$, dry weight $(\mathrm{DW}))>$ buds $(1364.05) \approx$ roots (without peel, 1058.83$) \approx$ stems part $(993.71) \approx$ blanched roots (without peel, 945.17) $\approx$ leaves $(881.16$ ). This result indicated that the total saponin levels were diverse according to individual parts of PG $(p<0.05)$, except for between the stem and root parts (without peel) $(p>0.05)$. As the ability to remove the PG peel was hindered, the total saponin content was significantly reduced $(p<0.05)$. This result was assumed to be due to the fact that the peel comprised a considerable number of saponins. In addition, the aerial parts, including stems and leaves, contained phenolic acid or flavonoids, instead of saponins, which induced a difference in the total saponin content between the roots and other parts $[35,41]$. Previous studies reported that the total contents of individual saponin derivatives were $6410 \sim 13,197$ (mg/100 g, DW) by quantifying based on corresponding external standards using HPLC [39,42,43]. Despite the use of external standards, an accurate confirmation of those compounds may be necessary for selecting authentic standards. HPLC could be limited in distinguishing simultaneously eluted saponins based on retention time. Other reports suggested that the total contents of crude saponins were 2524 and 23,400 (mg/100 g, DW) [44,45]; the analysis method for crude saponins induces a large difference in contents. In addition, quantification based on the internal standard, such as the method used in this study without external standards, could generate inaccurate data in terms of determining saponin contents only. Consequently, this study focused on the accurate identification of individual saponins using UPLC-QToF/MS, which is known as an instrument that indicates high resolutions, and then illustrated the proportion of individual saponin derivatives by comparing each sample in reference to quantification data based on the internal standard. In the case of stem parts, the deapi-platycodin D3 (peak $8,0.13 \%$ ) indicated the lowest proportion (\%) of the total content, whereas 3"-O-acetyl platycurodin D (peak 23, 8.32\%) was the highest proportion among the constituents. The two saponins are based on the aglycone of platycodigenin $(m / z 520)$. Accordingly, numerous studies using LC-MS show that deapi-platycodin D3 is clearly a minor compound [37,46,47]. The observed result of the bud parts was 2"-O-acetyl polygalacin D3 (peak 21, 0.36\%), which presented the lowest proportion (\%); this structure also belongs to the polygalacic acid $(m / z 504)$ group. In contrast, as based on platycogenic acid A $(m / z 534)$, the novel 2"-O-acetyl platyconic acid A (peak 38, 10.25\%) showed the highest proportion (\%) of the total content. In the leaves, 2"-O-acetyl platyconic acid A (peak 38, 11.55\%) was revealed as having the most obvious intensity, with the same in the bud case; conversely, the deapi-platycodin D2 (peak 19,0.37\%) showed the lowest concentration of intensity. Additionally, these compounds are associated with the aglycone of platycogenic acid A $(\mathrm{m} / \mathrm{z} 534)$ and platycodigenin $(\mathrm{m} / \mathrm{z} 520)$, respectively. Overall, in stems, buds, and leaves, the novel 2"-O-acetyl platyconic acid A (peak 38, 10.28, 10.25, 11.55\%) showed the most major saponin concentrations; this compound is based on the aglycone structure of platycogenic acid A $(m / z 534)$. The result of the roots (containing peel) was tentatively assigned as 3"-O-acetyl platyconic acid A3 (peak 13, 0.11\%), 
which indicated the lowest intensity and was based on platycodigenin $(\mathrm{m} / \mathrm{z} 520)$ aglycone; however, 3"-O-acetyl platycodin D (peak 27, 8.62\%) showed the highest concentration. After removing the peel of PG, the highest and lowest compounds were platycoside $\mathrm{E}$ (peak 3 , $9.62 \%$ ) and 3 "-O-acetyl platycoside $\mathrm{E}$ (peak 5, 0.02\%), and both were related to platycodigenin $(\mathrm{m} / \mathrm{z} 520)$ aglycone in this sample. Ultimately, saponins showing predominant contents in each sample were in the aglycone of the group in platycodigenin $(m / z 520)$, followed by platycogenic acid $\mathrm{A}(\mathrm{m} / \mathrm{z} 534)$.

Table 1. Saponin derivatives contents (mg/100 g, DW) of P. grandiflorum. Each value was calculated as mean $\pm \mathrm{SD}$ ( $\mathrm{n}=3$ ) using the internal standard (tubeimoside I 100 ppm); ND means "not detected"; contents were expressed in $\mathrm{mg} / 100 \mathrm{~g}$ DW (dry weight). Different small letters with mean values $(\mathrm{n}=3)$ reveal a significant difference (at $p<0.05)$ by Duncan's multiple range test.

\begin{tabular}{|c|c|c|c|c|c|c|c|}
\hline Aglycones & Peak No. ${ }^{(1)}$ & Stems & Buds & Leaves & $\begin{array}{c}\text { Roots } \\
\text { (Containing Peel) }\end{array}$ & $\begin{array}{c}\text { Roots } \\
\text { (without Peel) }\end{array}$ & $\begin{array}{l}\text { Blanched Roots } \\
\text { (without Peel) }\end{array}$ \\
\hline \multirow{12}{*}{$\begin{array}{l}\text { Polygalacic acid } \\
\qquad(\mathrm{m} / z 504)\end{array}$} & 4 & ND & ND & ND & $11.97 \pm 0.35^{\mathrm{a}}$ & $5.88 \pm 0.49^{b}$ & $4.60 \pm 0.34^{c}$ \\
\hline & 7 & ND & ND & ND & $7.14 \pm 0.15^{\mathrm{a}}$ & $3.95 \pm 0.19^{b}$ & $3.15 \pm 0.06^{c}$ \\
\hline & 11 & $29.89 \pm 3.67^{a}$ & ND & ND & $12.19 \pm 0.70^{b}$ & $11.56 \pm 1.06^{b}$ & $7.47 \pm 0.45^{c}$ \\
\hline & 13 & $10.54 \pm 1.30^{a}$ & $6.53 \pm 0.56^{b}$ & $4.85 \pm 2.55^{b}$ & $1.90 \pm 0.20^{c}$ & $2.02 \pm 0.49^{c}$ & ND \\
\hline & 14 & $11.51 \pm 2.02^{b}$ & $18.34 \pm 3.25^{a}$ & $18.11 \pm 1.94^{a}$ & $18.80 \pm 0.29^{a}$ & $11.68 \pm 0.56^{b}$ & $7.51 \pm 0.16^{c}$ \\
\hline & 16 & $6.41 \pm 0.97^{\mathrm{d}}$ & $15.46 \pm 1.48^{b}$ & $17.56 \pm 1.94^{\mathrm{a}}$ & $8.98 \pm 0.30^{c}$ & $2.52 \pm 0.40^{\mathrm{e}}$ & $2.93 \pm 0.23^{\mathrm{e}}$ \\
\hline & 18 & $9.02 \pm 1.82^{b c}$ & $61.97 \pm 11.76^{a}$ & $16.37 \pm 4.79^{b}$ & $3.83 \pm 0.48^{c}$ & $3.17 \pm 0.41^{c}$ & $0.97 \pm 0.16^{\mathrm{c}}$ \\
\hline & 21 & ND & $4.96 \pm 0.28^{b}$ & ND & $6.18 \pm 0.30^{\mathrm{a}}$ & $2.00 \pm 0.24^{\mathrm{d}}$ & $2.43 \pm 0.06^{\mathrm{c}}$ \\
\hline & 28 & $44.36 \pm 2.86^{b}$ & $65.53 \pm 7.09^{a}$ & $47.98 \pm 3.28^{b}$ & $42.28 \pm 4.49^{b}$ & $29.96 \pm 1.31^{c}$ & $26.22 \pm 0.51^{c}$ \\
\hline & 30 & $13.22 \pm 1.40^{c}$ & $16.94 \pm 3.76^{b}$ & ND & $35.96 \pm 0.75^{\mathrm{a}}$ & $12.39 \pm 1.30^{c}$ & $16.37 \pm 0.45^{b}$ \\
\hline & 36 & $37.51 \pm 1.04^{c}$ & $57.12 \pm 7.97^{a}$ & $46.63 \pm 5.02^{b}$ & $55.71 \pm 1.33^{a}$ & $29.99 \pm 6.74^{c}$ & $32.61 \pm 0.52^{c}$ \\
\hline & 37 & $14.01 \pm 2.33^{\mathrm{cd}}$ & $19.72 \pm 7.81^{c}$ & $45.45 \pm 3.09^{\mathrm{a}}$ & $26.73 \pm 2.40^{b}$ & $12.61 \pm 1.48^{\mathrm{d}}$ & $12.09 \pm 0.41^{\mathrm{d}}$ \\
\hline \multicolumn{2}{|c|}{ Subtotal } & $176.48 \pm 11.66^{c}$ & $266.56 \pm 26.94^{a}$ & $196.95 \pm 11.93^{c}$ & $233.41 \pm 4.97^{b}$ & $127.73 \pm 12.26^{d}$ & $116.33 \pm 1.39^{d}$ \\
\hline \multirow{4}{*}{$\begin{array}{c}\text { Platycogenic } \\
\text { acid A } \\
(m / z 534)\end{array}$} & 29 & ND & ND & ND & $9.09 \pm 2.05^{\mathrm{a}}$ & $6.95 \pm 0.41^{b}$ & $5.95 \pm 0.23^{b}$ \\
\hline & 31 & $17.15 \pm 2.60^{c}$ & $11.55 \pm 2.84^{\mathrm{d}}$ & ND & $28.25 \pm 1.84^{b}$ & $43.43 \pm 3.53^{a}$ & $18.90 \pm 1.07^{c}$ \\
\hline & 32 & $100.99 \pm 7.24^{b}$ & $125.92 \pm 4.94^{\mathrm{a}}$ & $97.42 \pm 3.12^{b}$ & $126.91 \pm 3.01^{\mathrm{a}}$ & $80.98 \pm 7.62^{c}$ & $85.44 \pm 5.35^{c}$ \\
\hline & 38 & $102.18 \pm 1.51^{b}$ & $139.78 \pm 12.81^{\mathrm{a}}$ & $101.78 \pm 5.71^{b}$ & $134.30 \pm 0.91^{\mathrm{a}}$ & $87.79 \pm 3.14^{c}$ & $90.84 \pm 1.31^{c}$ \\
\hline \multicolumn{2}{|c|}{ Subtotal } & $220.32 \pm 9.73^{c}$ & $277.24 \pm 15.34^{b}$ & $199.20 \pm 8.77^{d}$ & $298.55 \pm 2.83^{a}$ & $219.15 \pm 8.82^{c}$ & $201.13 \pm 5.47^{d}$ \\
\hline \multirow{22}{*}{$\begin{array}{l}\text { Platycodigenin } \\
\quad(m / z 520)\end{array}$} & 1 & ND & ND & ND & $8.69 \pm 0.05^{a}$ & $2.82 \pm 0.12^{c}$ & $3.07 \pm 0.19^{b}$ \\
\hline & 2 & ND & ND & ND & $69.69 \pm 2.33^{a}$ & $34.19 \pm 0.83^{b}$ & $31.62 \pm 0.44^{c}$ \\
\hline & 3 & ND & ND & ND & $139.10 \pm 3.00^{\mathrm{a}}$ & $101.90 \pm 3.51^{b}$ & $94.68 \pm 3.05^{c}$ \\
\hline & 5 & ND & ND & ND & $1.96 \pm 0.25^{\mathrm{a}}$ & $0.18 \pm 0.04^{\mathrm{b}}$ & ND \\
\hline & 6 & ND & ND & ND & ND & ND & $1.73 \pm 0.11^{\mathrm{a}}$ \\
\hline & 8 & $1.28 \pm 0.75^{\mathrm{d}}$ & ND & $7.44 \pm 5.58^{c}$ & $32.72 \pm 1.33^{a}$ & $13.04 \pm 0.61^{\mathrm{b}}$ & $9.71 \pm 0.30^{\mathrm{bc}}$ \\
\hline & 9 & ND & ND & ND & $10.19 \pm 0.34^{\mathrm{a}}$ & $4.76 \pm 0.40^{\mathrm{b}}$ & $2.46 \pm 0.11^{c}$ \\
\hline & 10 & $26.28 \pm 3.96^{c}$ & $29.59 \pm 1.75^{c}$ & $57.62 \pm 41.45^{b c}$ & $101.21 \pm 6.13^{\mathrm{a}}$ & $69.83 \pm 2.35^{b}$ & $56.32 \pm 0.93 \mathrm{bc}$ \\
\hline & 12 & $23.94 \pm 21.17^{b}$ & ND & ND & $44.19 \pm 0.85^{\mathrm{a}}$ & $18.85 \pm 2.01^{\mathrm{b}}$ & $14.15 \pm 0.25^{b c}$ \\
\hline & 15 & ND & ND & ND & $6.11 \pm 0.32^{\mathrm{a}}$ & $1.90 \pm 0.30^{\mathrm{b}}$ & $1.55 \pm 0.16^{\mathrm{c}}$ \\
\hline & 17 & $12.80 \pm 1.75^{c}$ & $30.92 \pm 5.84^{b}$ & ND & $36.93 \pm 0.47^{a}$ & $11.96 \pm 1.54^{c}$ & $9.75 \pm 0.35^{c}$ \\
\hline & 19 & ND & ND & $3.24 \pm 0.36^{\mathrm{d}}$ & $25.33 \pm 0.60^{a}$ & $19.94 \pm 1.03^{b}$ & $10.53 \pm 0.10^{c}$ \\
\hline & 20 & $65.01 \pm 2.95^{\mathrm{a}}$ & $68.65 \pm 8.04^{a}$ & $37.89 \pm 3.59^{b}$ & $21.15 \pm 0.60^{c}$ & $24.23 \pm 0.14^{c}$ & $13.86 \pm 0.69^{d}$ \\
\hline & 22 & ND & $46.52 \pm 36.97^{\mathrm{a}}$ & $12.37 \pm 0.56^{\mathrm{b}}$ & $24.41 \pm 1.58^{\mathrm{ab}}$ & $6.90 \pm 1.46^{b}$ & $9.51 \pm 0.35^{\mathrm{b}}$ \\
\hline & 23 & $82.66 \pm 3.88^{a}$ & $71.87 \pm 46.73^{\mathrm{a}}$ & $51.96 \pm 4.47 \mathrm{ab}$ & $23.41 \pm 2.13^{b c}$ & $11.68 \pm 2.03^{c}$ & $16.72 \pm 1.13^{b c}$ \\
\hline & 24 & $22.39 \pm 1.78^{b c}$ & $26.05 \pm 17.72^{b c}$ & $17.17 \pm 1.20^{c}$ & $48.10 \pm 0.91^{\mathrm{a}}$ & $50.18 \pm 2.48^{a}$ & $32.92 \pm 1.32^{b}$ \\
\hline & 25 & $24.74 \pm 2.06^{\mathrm{d}}$ & $27.89 \pm 4.08^{\mathrm{d}}$ & $8.97 \pm 0.53^{\mathrm{e}}$ & $85.93 \pm 2.02^{b}$ & $93.19 \pm 7.50^{a}$ & $50.59 \pm 1.14^{c}$ \\
\hline & 26 & $62.75 \pm 3.21^{c}$ & $94.67 \pm 4.48^{a}$ & $61.79 \pm 5.51^{\mathrm{c}}$ & $82.98 \pm 2.59^{b}$ & $57.48 \pm 4.15^{\mathrm{cd}}$ & $52.40 \pm 1.63^{\mathrm{d}}$ \\
\hline & 27 & $78.64 \pm 1.80^{\mathrm{cd}}$ & $105.65 \pm 4.28^{b}$ & $67.48 \pm 3.28^{\mathrm{e}}$ & $144.40 \pm 4.29^{\mathrm{a}}$ & $73.97 \pm 6.88$ de & $81.54 \pm 1.06^{c}$ \\
\hline & 33 & $81.17 \pm 4.37^{b}$ & $134.72 \pm 6.54^{\mathrm{a}}$ & $62.52 \pm 2.61^{c}$ & $37.38 \pm 3.36^{d}$ & $21.74 \pm 1.13^{e}$ & $25.60 \pm 1.08^{e}$ \\
\hline & 34 & $49.89 \pm 3.05^{c}$ & $93.62 \pm 4.73^{\mathrm{a}}$ & $41.38 \pm 2.69^{d}$ & $77.16 \pm 2.21^{b}$ & $38.37 \pm 3.73^{d}$ & $40.05 \pm 0.85^{d}$ \\
\hline & 35 & $65.39 \pm 3.99 \mathrm{~cd}$ & $90.09 \pm 6.35^{b}$ & $55.17 \pm 5.51^{\mathrm{d}}$ & $123.33 \pm 4.00^{\mathrm{a}}$ & $54.84 \pm 13.52^{\mathrm{d}}$ & $68.87 \pm 1.11^{c}$ \\
\hline \multicolumn{2}{|c|}{ Subtotal } & $596.91 \pm 40.90^{d}$ & $820.24 \pm 35.85^{b}$ & $485.01 \pm 23.31^{e}$ & $1144.37 \pm 18.86^{a}$ & $711.95 \pm 28.26^{c}$ & $627.71 \pm 8.24^{d}$ \\
\hline \multicolumn{2}{|c|}{ Total } & $993.71 \pm 57.27 \mathrm{~cd}$ & $1364.05 \pm 73.40^{b}$ & $881.16 \pm 5.15^{\mathrm{e}}$ & $1674.60 \pm 25.45^{a}$ & $1058.83 \pm 45.69^{c}$ & $945.17 \pm 11.08^{\text {de }}$ \\
\hline & & $\begin{array}{l}\text { (1) } 1 \text {, platycosic } \\
\text { platycoside E; } \\
\text { platycoside E; } 1 \\
\text { acid A3; 14, po } \\
\text { platycodin D3; } \\
\text { 2"-O-acetyl pol } \\
\text { platycodin D2; } \\
\text { 3"-O-acetyl pol } \\
\text { platyconic acid } \\
\text { platycodin D2 } \\
\text { 2"-O-acetyl pol }\end{array}$ & $\begin{array}{l}\text { G2; } 2 \text {, platycosic } \\
\text { platycoside P; } 7 \\
\text { platycodin D3; } 1 \\
\text { galacin D3; } 15 \text {, de } \\
3,2 \text { "-O-acetyl plat } \\
\text { ralacin D3; 22, de } \\
\text { 5, platycodin D; } \\
\text { yalacin D2; 29, 2"- } \\
\text {; 32, 3"-O-acetyl } \\
\text { latycodin V); 35, } \\
\text { galacin D; 38, 2"- }\end{array}$ & $\begin{array}{l}\text { G1(deapi-platy } \\
\text { platycoside I(de } \\
\text { platyconic acid } \\
\text { oi-2"-O-acetyl pl } \\
\text { zonic acid A3; } 19 \\
\text { i-3"-O-acetyl pla } \\
\text { 3"-O-acetyl pla } \\
\text {-acetyl platyconi } \\
\text { tyconic acid A; } \\
\text { '-O-acetyl platy } \\
\text { acetyl platyconi }\end{array}$ & $\begin{array}{l}\text { ide E); 3, platyco } \\
\text { i-polygalacin E); } \\
\text {; } 12,3^{\prime \prime}-\mathrm{O} \text {-acetyl pl } \\
\text { codin D3; } 16,3^{\prime \prime}-( \\
\text { eapi-platycodin D2 } \\
\text { odin D2; 23, 3"-O- } \\
\text { codin D2; 27, 3"-O } \\
\text { cid C(platyconic ac } \\
\text { 2"-O-acetyl platyc } \\
\text { din D(platycodin } \\
\text { cid A. }\end{array}$ & $\begin{array}{l}\text { e E; } 4 \text {, platycosic } \\
\text { deapi-platycodin } \\
\text { ycodin D3; } 13,3 \text { "- } \\
\text { cetyl polygalacin } \\
\text { latycoside A); } 20 \text {, } \\
\text { etyl platycurodin } \\
\text { etyl platycodin } \\
\text { D); } 30,3^{\prime \prime}-O \text {-acet } \\
\text { odin D(platycodir } \\
36,2 \text { "-O-acetyl }\end{array}$ & $\begin{array}{l}\mathrm{D} ; 5,3 \text { "-O-acety } \\
\mathrm{D} 3 ; 9,2 \text { "-O-acety } \\
\text { O-acetyl platyconi } \\
\mathrm{D} 3 ; 17,2^{\prime \prime}-O \text {-acety } \\
\text { olatycurodin D; } 2 \\
\text { (platycodin L); } 2 \\
\text { (platycodin C); } 2 \\
\text { l polygalacin D; } 3 \\
\mathrm{~K}) ; 34,2^{\prime \prime}-\mathrm{O} \text {-acety } \\
\text { olygalacin D2; } 3\end{array}$ \\
\hline
\end{tabular}




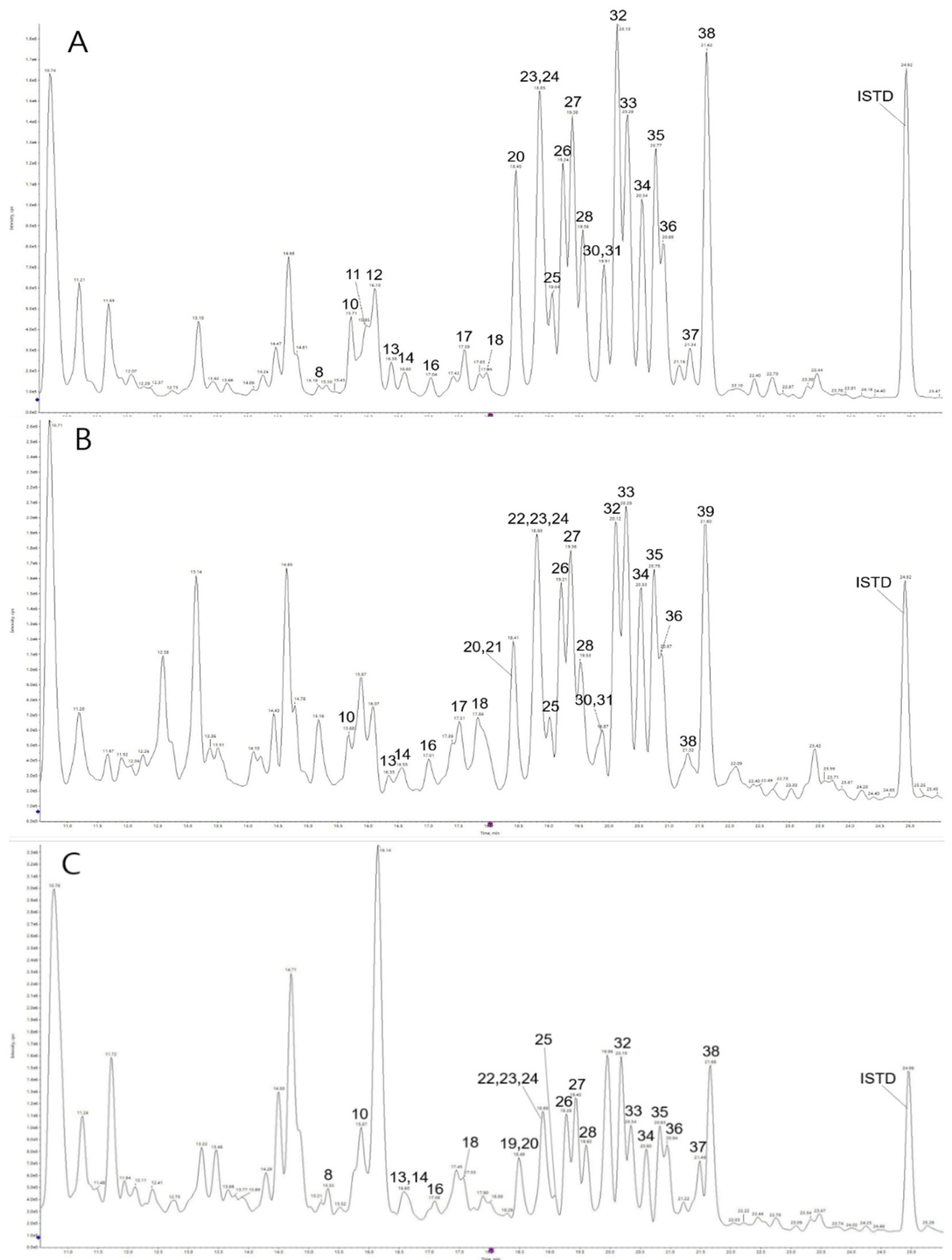

Figure 2. UPLC chromatograms of saponins from Platycodon grandiflorum. (A) stems part, (B) buds parts, and (C) leaves part. 

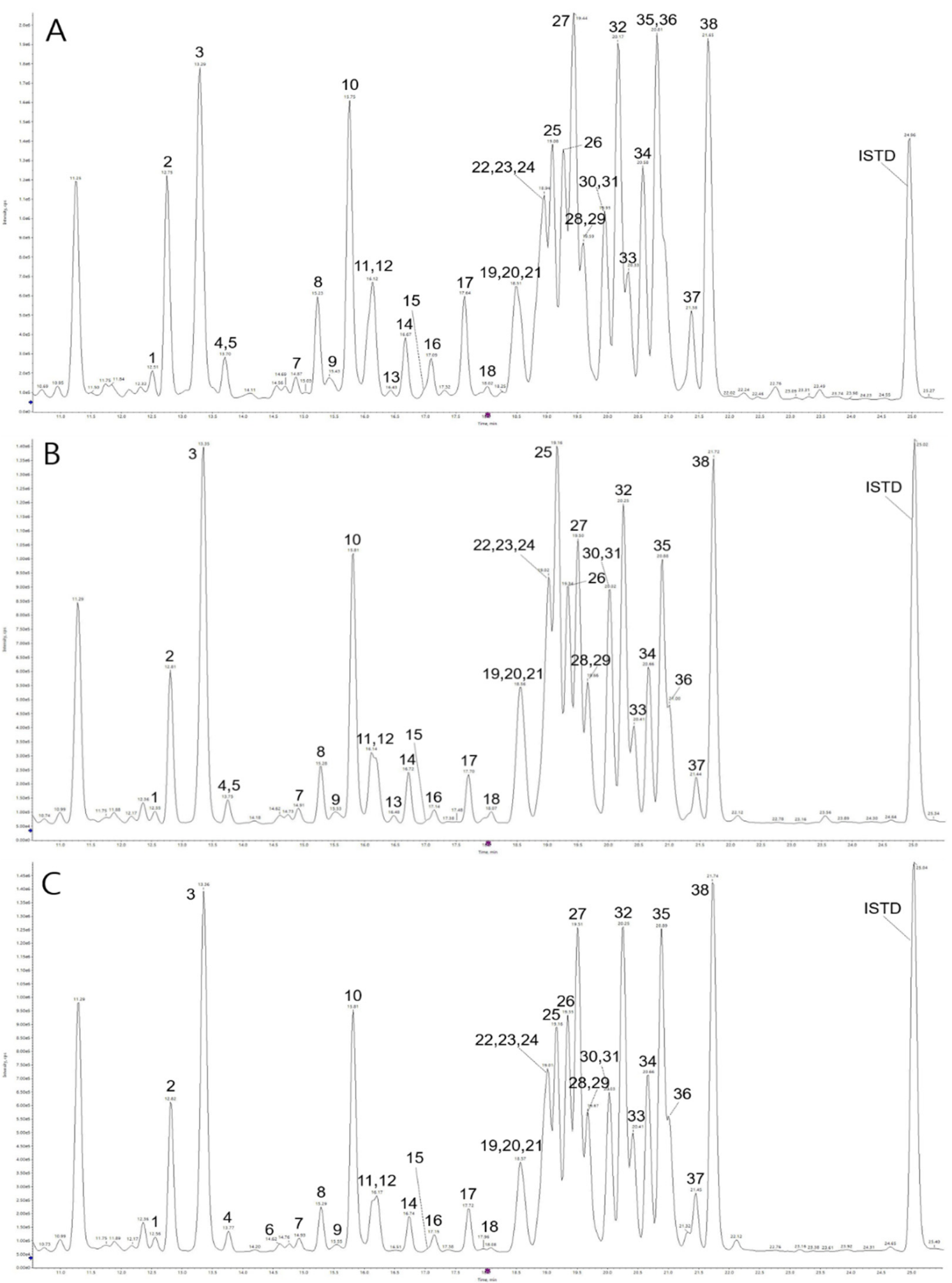

Figure 3. UPLC chromatograms of 38 saponins from Platycodon grandiflorum. (A) roots (containing peel), (B) roots (without peel), and (C) blanched roots (without peel).

In addition, among the aglycone groups, the triterpenoid saponin related to platycodigenin (55.04-68.34\%) was significantly more abundant than platycogenic acid A (17.83-22.61\%) and polygalacic acid (12.06-22.35\%). The compounds were related to the aglycone of platycodigenin $(m / z 520)$, and 10 saponins of the 22 derivatives belonged to this group, indicating 
their significant difference $(p<0.05)$. They are the following compounds: platycoside G2 (peak 1), platycoside G1 (peak 2), platycoside E (peak 3), 3"-O-acetyl platycoside E (peak 5), platycoside P (peak 6), deapi-platycodin D3 (peak 8), 2"-O-acetyl platycoside E (peak 9), deapi-2"-O-acetyl platycodin D3 (peak 15), deapi-platycodin D2 (peak 19), and 2"-O-acetyl platycurodin D (peak 33); these do not include the undetected saponins. Additionally, in the platycogenic acid A ( $m / z$ 534) group, 2"-O-acetyl platyconic acid C (peak 29) and platyconic acid A (peak 31) indicated significant differences $(p<0.05)$. The remaining 3 "'-O-acetyl platyconic acid A (peak 32) and 2"-O-acetyl platyconic acid A (peak 38) groups showed no meaningful differences $(p>0.05)$. Moreover, in the case of polygalacic acid $(\mathrm{m} / \mathrm{z} 504)$, only four compounds, including platycoside D (peak 4), deapi-polygalacin E (peak 7), 3"-O-acetyl polygalacin D3 (peak 16), and 2"-O-acetyl polygalacin D3 (peak 21), indicated meaningful differences $(p<0.05)$, whereas the others in this group were compounds that showed no significant differences $(p>0.05)$.

By focusing on these novel compounds in the aglycone group of polygalacic acids, deapi-polygalacin E (peak 7, 3.01\%) was detected as a significant proportion of the total saponin contents in the stems, which was comparable to other parts. Additionally, 2"-Oacetyl platyconic acid A3 (peak 18, 4.54\%) was predominantly indicated in the buds. In the case of the platycogenic acid A group, 2"-O-acetyl platyconic acid A (peak 38, $8.02 \sim 11.55 \%$ ) and 3"-O-acetyl platyconic acid A (peak 32, $7.58 \sim 11.06 \%$ ) were detected as major saponins. Finally, the results of platycodigenin aglycone group showed that platycurodin D (peak 20) occupied a significant proportion of the stems and buds, representing $6.54 \%$ and $5.03 \%$ of the total contents, respectively.

Previous studies reported that platycodin D or polygalacin D were the most dominant saponin derivative, and the contents of each compound indicated values as diverse as $246.2 \sim 1196.9$ (mg/100 g, DW) and $191.6 \sim 1241.0$ (mg/100 g, DW) when changing soil conditions, dividing the root, and changing the cultivated region [31,48-53]. However, Lu et al. showed that for the individual saponin content of various cultivated regions, some provinces revealed platycoside E $(69.1 \sim 346.2 \mathrm{mg} / 100 \mathrm{~g}$, DW $)$ to be the most prevalent compound; however, other regions showed platycodin D (40.9 511.3 mg/100 g, DW) to be the predominant compound [42]. Therefore, these results indicated that the content and composition of individual saponins could differ dramatically by region. Many previous reports suggested that platycodin $\mathrm{D}$ and polygalacin $\mathrm{D}$ were major compounds. However, this study showed that 2"-O-acetyl platyconic acid A (peak 38, $101.78 \sim 139.78 \mathrm{mg} / 100 \mathrm{~g}$, DW), a tentatively identified novel saponin, was detected as the most prevalent compound in the stem, bud, and leaves of PG using UPLC-QToF/MS. Additionally, the predominant saponins in the roots containing peel were 3 "-O-acetyl platycodin $\mathrm{D}$ (peak 27, $144.40 \mathrm{mg} / 100 \mathrm{~g}, \mathrm{DW}$ ) and platycoside E (peak 3, $101.90 \mathrm{mg} / 100 \mathrm{~g}$, DW) in the roots without the peel, respectively.

With reference to the table detailing saponin contents in roots (without peel) and blanched roots (without peel), the total saponin was reduced from 1058.83 (mg/100 g, DW) to 945.17 (mg/100 g, DW) after blanching (Table 1). Additionally, in the polygalacic acid group $(\mathrm{m} / \mathrm{z} 504)$, one of the three groups, tentatively identified as novel compound 3"-O-acetyl platyconic acid A3 (peak 13), was removed entirely due to blanching. The proportion of polygalacin D3 (peak 14), 2"-O-acetyl polygalacin D (peak 37), and 3"'-Oacetyl polygalacin D2 (peak 28) on the total saponin in each sample decreased after the process. Conversely, the contents of $3^{\prime \prime}-O$-acetyl polygalacin D3 (peak 16), 2"-O-acetyl polygalacin D3 (peak 21), 3"-O-acetyl polygalacin D (peak 30), and 2"-O-acetyl polygalacin D2 (peak 36) were higher than before blanching. These results indicate that acetylation from polygalacin D3 to two compounds, including 3"-O-acetyl polygalacin D3 (peak 16) and 2"$O$-acetyl polygalacin D3 (peak 21), might occur during the blanching process. Additionally, the trans-acetylation from 2 "-O-acetyl polygalacin D (peak 37) to 3"-O-acetyl polygalacin D (peak 30), as well as from 3"-O-acetyl polygalacin D2 (peak 28) to 2"-O-acetyl polygalacin D2 (peak 36), was assumed to occur simultaneously due to the migration between $3{ }^{\prime \prime}-\mathrm{O}-$ acetyl and 2"-O-acetyl by each specific enzyme. In the case of the platycogenic acid A group 
$(m / z 534)$, platyconic acid A (peak 31) decreased after the process, whereas the proportional contents of 3"-O-acetyl platyconic acid A (peak 32) and 2"-O-acetyl platyconic acid A (peak 38) increased. Finally, in the platycodigenin group $(m / z 520)$, platycoside G2 (peak 1 ) lacked xyloside from platycoside G1 (peak 2), and was reduced in the blanching procedure; in contrast, the latter increased. By the mechanism of de-xylosylation and acetylation, deapi-platycodin D2 (peak 19) might be converted to corresponding platycoside P (peak 6) and deapi-3"-O-acetyl platycodin D2 (peak 22), respectively. Similarly, the phenomenon of decreasing platycurodin D (peak 20), platycodin D (peak 25), and platycodin D2 (peak 24) was presumed to change into 3 or 2"-O-acetyl platycurodin D (peak 23, 33), 3 or 2"-O-acetyl platycodin D (peak 27, 35), and 2"-O-acetyl platycodin D2 (peak 34) during the process with the use of acetic acid. Additionally, 2"-O-acetyl platycodin D2 (peak 34) might be converted from 3"-O-acetyl platycodin D2 (peak 26) by the migration of the acetic acid position from $3-\mathrm{OH}$ to $2-\mathrm{OH}$ by a trans-acetylation mechanism. Previous studies reported that specific enzymes have the ability to transform from platycoside E (peak 3) and platycodin D3 (peak 10) to platycodin D (peak 25) through the removal of glucoside [2,53,54]. Likewise, xylosylation was predicted to occur with a similar mechanism during the blanching process. Additionally, in the case of astragaloside from Radix Astragali in the saponin group, the optimal temperature for acetyl estrase's activity was $35^{\circ} \mathrm{C}$, and it was stable at temperatures lower than $45^{\circ} \mathrm{C}$ [55]. Nyakudya et al. noted the platycodin pathway in the enzymatic transformation by human intestinal microorganisms; this finding reinforces the acetylation mechanism, as well as de-glycosylation, including glucose and xylose, in PG [39]. Ma et al. reported that the cytochrome P450 (CYPs), polygalacic acid, platycodigenin, and platycogenic acid A are converted by one another; they also found that glycosyl transferase affects the detachment of carbohydrates in PG [38]. Therefore, in this study, using a blanching procedure, the mechanism of acetylation might have occurred in the provided temperature $\left(35 \sim 45^{\circ} \mathrm{C}\right)$ over a short time $(2 \mathrm{~min})$ because the core temperature of PG is satisfied with these specific conditions. Additionally, de-xylosylation could be illustrated in the phenomenon of de-glycosylation.

In all of the published literature, it is clear that Platycodon grandiflorum saponins (PGS) are oleanane types of triterpenoids $[46,56]$. PGS have hepato-protective effects by blocking the bioactivation of $\mathrm{CCl}_{4}$ and scavenging free radicals while inhibiting CYP2E1 activity [57]. In addition, PGS can also be immunological adjuvants. One of the PGS, platycodin D2, has potential to be a safe adjuvant that increases Th1 and Th2 cytokines $[35,58]$. Platycodin D could be used for the treatment of cancer via the induction of apoptosis in human leukocytes [11]. Moreover, it may be a potent adjuvant for increasing immune responses against the hepatitis B antigen [59]. 2"-O-acetyl polygalacin D2 and platycodin D were reported to reduce neuroinflammation [60]. Platycodin D3 regulates the production of NO (nitric oxide) and TNF- $\alpha$, resulting in inflammatory pulmonary diseases [61,62]. Furthermore, a previous study reported a relationship between structure and function on seven major saponins from PG, and the result of this study was that platycodin D could be a major constituent for its strong immunological adjuvant properties and hemolytic activity [63].

In the above mentioned reports, major saponins, such as platycodin D and polygalacin $\mathrm{D}$, were detected by a comparatively less accurate method: liquid chromatography (LC). This method is less accurate than LC coupled mass spectrometry (MS), which was used in this study. The results of this study provide the chromatographic and mass fragment data of individual saponins, tentatively identified by an accurate method: UPLC-QToF/MS. Accordingly, the compounds detected by this method include 2"-O-acetyl platyconic A (peak 38), 3"-O-acetyl platycodin D (peak 27), and platycoside E (peak 3) as the most prevalent constituents, which themselves could be separated and purified to produce health functional foods; moreover, the significantly large proportion of 2"-O-acetyl platyconic A could be used in various industries. In addition, in terms of their meaningful difference in saponin content, buds may be utilized in health functional foods. 


\section{Materials and Methods}

\subsection{Chemicals and Reagents}

Methanol and water (HPLC grade) were purchased from Fisher Scientific (Fair Lawn, NJ, USA). Deapi-platycoside E, platycodin D3, platycodin D, and polygalacin D were purchased from Target Molecule Corporation (Boston, MA, USA), and platycoside E, platycodin D2, deapi-platycodin D3, and deapi-platycodin D were purchased from Med Chem Express (Monmouth, NJ, USA), whereas 3"-O-acetylplatyconic acid A from ALB Tech (Albany, NY, USA) was used as an external standard for identification. Tubeimoside I was used as the internal standard (100 ppm).

\subsection{Plant Materials}

Roots of P. grandiflorum were collected from Hoengseong, Korea in 2020. Leaves, stems, and buds of P. grandiflorum were obtained from Icheon, Korea in 2019. One part of the roots was blanched at $100^{\circ} \mathrm{C}$ for $2 \mathrm{~min}$ after being washed with water, and the remains were only washed without blanching. Then, all samples were freeze-dried, pulverized, and stored in a deep freezer before analysis.

\subsection{Extraction of Saponins}

Then, $0.1 \mathrm{~g}$ of powered samples was extracted, first with $1.5 \mathrm{~mL}$, and then with $1 \mathrm{~mL}$ extraction solvent $(70 \%$ methanol). The mixture of the two extractions was vortexed, centrifuged for $10 \mathrm{~min}$ at $13,000 \mathrm{rpm}, 10^{\circ} \mathrm{C}$, and the supernatant was filtered using a syringe filter (PVDF $0.2 \mu \mathrm{m}, 13 \mathrm{~mm}$, Whatman, Kent, England). The saponin extract was concentrated using $\mathrm{N}_{2}$ gas and redissolved with $15 \mathrm{~mL}$ of water. A solid-phase extraction method using a Hypersep C18 cartridge (Thermo Scientific, Rockwood, TN, USA) was initiated to isolate saponin derivates from the extract. The cartridge was activated with methanol $(3 \mathrm{~mL})$, followed by water $(6 \mathrm{~mL})$ for conditioning. The redissolved saponin extract was loaded on the cartridge, and then the diluted solution containing ISTD (internal standard; $100 \mathrm{ppm}$ ) was loaded on the cartridge. After washing the cartridge with water $(6 \mathrm{~mL})$, the crude saponin extract was eluted by methanol $(15 \mathrm{~mL})$ and concentrated using $\mathrm{N}_{2}$ gas. The final extract was redissolved with $500 \mu \mathrm{L}$ of the extraction solvent $(70 \%$ methanol) and filtered by a syringe filter (PVDF $0.2 \mu \mathrm{m}, 13 \mathrm{~mm}$, Whatman, Kent, England).

\subsection{UPLC-DAD-QToF/MS Analysis}

Saponin derivative profiling was performed by UPLC-DAD-QToF/MS (Sciex Co., Framingham, MA, USA) (Tables 2 and 3). Identification and quantification of saponins were conducted by an analysis software version (Sciex Co., USA).

Table 2. MS parameters for saponin analysis.

\begin{tabular}{cc}
\hline Items & Conditions \\
\hline Ion source gas $(\mathrm{psi})$ & 50 \\
\hline Curtain gas $(\mathrm{psi})$ & 30 \\
\hline Ion source temperature $\left({ }^{\circ} \mathrm{C}\right)$ & 450 \\
\hline Declustering potential $(\mathrm{V})$ & 80 \\
\hline Collision energy $(\mathrm{V})$ & $15 \pm 10$ \\
\hline Spray voltage $(\mathrm{V})$ & 5500 \\
\hline CE spread $(\mathrm{V})$ & 10 \\
\hline Ionization mode & Positive \\
\hline Mass range $(m / z)$ & $100-2000$
\end{tabular}


Table 3. UPLC separation conditions for saponin analysis.

\begin{tabular}{|c|c|}
\hline Items & Conditions \\
\hline Column & CORTECS ${ }^{\circledR} \mathrm{UPLC}^{\circledR} \mathrm{T} 3,2.1 \times 150 \mathrm{~mm}, 1.6 \mu \mathrm{m}$ \\
\hline Pre-column & CORTECS ${ }^{\circledR}$ UPLC $^{\circledR}$ Vanguard T3, $2.1 \times 50 \mathrm{~mm}, 1.6 \mu \mathrm{m}$ \\
\hline Column temperature & $30{ }^{\circ} \mathrm{C}$ \\
\hline Detector & 190-400 nm (representative wavelength, $203 \mathrm{~nm}$ ) \\
\hline Mobile phase & $\begin{array}{l}\text { A: } 0.1 \% \text { Formic acid in water } \\
\text { B: } 0.1 \% \text { Formic acid in acetonitrile }\end{array}$ \\
\hline Injection volume & $1 \mu \mathrm{L}$ \\
\hline Flow & $0.35 \mathrm{~mL} / \mathrm{min}$ \\
\hline Running time & $60 \mathrm{~min}$ \\
\hline Gradient condition & $\begin{array}{c}0-10 \min (15-25 \% \text { B }), 10-40 \min (25-50 \% \text { B }), 40-45 \min \\
(50-15 \% \text { B }), 50-60 \min (15 \% \text { B })\end{array}$ \\
\hline
\end{tabular}

\subsection{Identification and Quantification of Saponin Derivatives}

The saponin library for Platycodon grandiflorum was constructed by data from the previous literature, as confirmed by MS and NMR analyses (Table S1). Saponin derivatives were identified by the data of these libraries, comprising compound names, used parts, molecular weight, and MS fragment ion patterns. Based on 9 standards confirmed and selected by multiple reaction monitoring (MRM) of Platycodon grandiflorum, 39 saponin derivatives were identified. Quantification was implemented by calculating the relative peak area of compounds compared with the internal standard (tubeimoside I, $100 \mathrm{ppm}$ ).

\subsection{Statistical Analysis}

One-way ANOVA was performed to confirm a significant difference between individual averages using Duncan's multiple range test $(p<0.05)$ in SPSS (version 25.0, SPSS Inc., Chicago, IL, USA).

\section{Conclusions}

The objective of this study was to provide comprehensive data related to the chromatographic and mass fragment ion patterns of the 38 saponin derivatives in relation to four parts of Platycodon grandiflorum: stems, roots, leaves, and buds. Our method was based on a library constructed of the findings from previous literature, and newly detected data in this study allowed us to tentatively identify novel compounds to support further studies. In this study, except for the well-known major saponins, such as platycodin D, tentatively identified novel saponins indicated larger peaks than those in the abovementioned major compounds. Though the roots of PG have been comprehensively studied, studies on the buds and individual saponins, including novel and minor compounds, remain necessary; furthermore, their activities in relation to human health should also be studied. In conclusion, we provided chromatographic and mass fragment ion pattern data of 38 saponins from four parts of PG; peeling (or not) and blanching may be used in diverse experiments related to their characterization, and may aid in the production of functional food for human consumption.

Supplementary Materials: The following are available online: Table S1: Chemical library of 70 saponin derivatives based on previous literature sources. Table S2: Characterization of 38 saponin derivatives in Platycodon grandiflorum.

Author Contributions: S.H.L. conceived of the project; S.-J.L., H.-W.K., and S.H.L. designed the experiments; S.L., R.H.K., H.N., J.H.K., C.-D.W., and S.M.Y. prepared the samples; S.-J.L., R.H.K., H.N., and J.H.K. analyzed the data; S.-J.L. wrote the article. All authors have read and agreed to the published version of the manuscript. 
Funding: This research was supported by the National Institute of Agricultural Sciences, rural development administration of Korea; Saponin database project (PJ014176012021).

Institutional Review Board Statement: Not applicable.

Informed Consent Statement: Not applicable.

Data Availability Statement: The data that support the results and findings of this study is available from the corresponding author upon request.

Conflicts of Interest: The authors declare no conflict of interest.

Sample Availability: Samples of the compounds are not available from the authors.

\section{References}

1. Jeong, C.-H.; Choi, G.N.; Kim, J.H.; Kwak, J.H.; Kim, D.O.; Kim, Y.J.; Heo, H.J. Antioxidant activities from the aerial parts of Platycodon grandiflorum. Food Chem. 2010, 118, 278-282. [CrossRef]

2. Jeong, E.-K.; Ha, I.J.; Kim, Y.S.; Na, Y.-C. Glycosylated platycosides: Identification by enzymatic hydrolysis and structural determination by LC-MS/MS. J. Sep. Sci. 2014, 37, 61-68. [CrossRef]

3. $\quad$ Liu, Y.-Y.; Wang, Y.; Lv, W.-Q.; Li, D.; Wang, L.-J. Freeze-thaw and ultrasound pretreatment before microwave combined drying affects drying kinetics, cell structure and quality parameters of Platycodon grandiflorum. Ind. Crops Prod. 2021, 164, 113391. [CrossRef]

4. Wang, C.; Zhang, N.; Wang, Z.; Qi, Z.; Zheng, B.; Li, P.; Liu, J. Rapid characterization of chemical constituents of Platycodon grandiflorum and its adulterant Adenophora stricta by UPLC-QTOF-MS/MS. J. Mass Spectrom. 2017, 52, 643-656. [CrossRef] [PubMed]

5. Wang, C.; Zhang, N.; Wang, Z.; Qi, Z.; Zhu, H.; Zheng, B.; Li, P.; Liu, J. Nontargeted metabolomic analysis of four different parts of Platycodon grandiflorum grown in Northeast China. Molecules 2017, 22, 1280. [CrossRef] [PubMed]

6. Xu, B.-J.; Zheng, Y.-N.; Sung, C.-K. Quality control and evaluation of Platycodon grandiflorum: Implications for future management. Nat. Prod. Sci. 2004, 10, 141-151.

7. $\quad$ Lee, Y.-J.; Lee, H.-O.; Kim, J.-Y.; Kwon, K.-H.; Cha, H.-S.; Kim, B.-S. Quality characteristics of frozen doraji (Platycodon grandiflorum) according to various blanching treatment conditions. Korean J. Food Preserv. 2011, 18, 661-668. [CrossRef]

8. Yuk, T.; Sung, J.; Han, H.M.; Kim, Y.; Jeong, H.S.; Lee, J. Effect of different cooking methods on phytochemical content and antioxidant capacity of Platycodon grandiflorum root. Food Sci. Biotechnol. 2015, 24, 1597-1602. [CrossRef]

9. Choi, Y.H.; Yoo, D.S.; Cha, M.R.; Choi, C.W.; Kim, Y.S.; Choi, S.U.; Lee, K.R.; Ryu, S.Y. Antiproliferative Effects of Saponins from the Roots of Platycodon grandiflorum on Cultured Human Tumor Cells. J. Nat. Prod. 2010, 73, 1863-1867. [CrossRef]

10. Kim, J.-Y.; Park, K.-W.; Moon, K.-D.; Lee, M.-K.; Choi, J.; Yee, S.-T.; Shim, K.-H.; Seo, K.-I. Induction of apoptosis in HT-29 colon cancer cells by crude saponin from Platycodi Radix. Food Chem. Toxicol. 2008, 46, 3753-3758. [CrossRef]

11. Kim, M.-O.; Moon, D.-O.; Choi, Y.H.; Shin, D.Y.; Kang, H.S.; Choi, B.T.; Lee, J.-D.; Li, W.; Kim, G.-Y. Platycodin D induces apoptosis and decreases telomerase activity in human leukemia cells. Cancer Lett. 2008, 261, 98-107. [CrossRef]

12. Qiu, L.; Xiao, Y.; Liu, Y.Q.; Peng, L.X.; Liao, W.; Fu, Q. Platycosides P and Q, two new triterpene saponins from Platycodon grandiflorum. J. Asian Nat. Prod. Res. 2018, 21, 419-425. [CrossRef]

13. Zhao, H.L.; Sim, J.-S.; Shim, S.H.; Ha, Y.W.; Kang, S.S.; Kim, Y.S. Antiobese and hypolipidemic effects of platycodin saponins in diet-induced obese rats: Evidences for lipase inhibition and calorie intake restriction. Int. J. Obes. 2005, 29, 983-990. [CrossRef] [PubMed]

14. Zhao, L.-C.; Liu, Y.; Wang, Z.; Tang, N.; Leng, J.; Zheng, B.; Liu, Y.-Y.; Li, W. Liquid chromatography/mass spectrometry analysis and hepatoprotective effect of steamed Platycodi Radix on acute alcohol-induced liver injury. Int. J. Pharmacol. 2018, 14, 952-962. [CrossRef]

15. Arif, T.; Bhosale, J.D.; Kumar, N.; Mandal, T.K.; Bendre, R.S.; Lavekar, G.S.; Dabur, R. Natural products-antifungal agents derived from plants. J. Nat. Prod. 2009, 11, 621-638. [CrossRef] [PubMed]

16. Faizal, A.; Geelen, D. Saponins and their role in biological processes in plants. Phytochem. Rev. 2013, 12, 877-893. [CrossRef]

17. Miettinen, K.; Inigo, S.; Kreft, L.; Pollier, J.; De Bo, C.; Botzki, A.; Coppens, F.; Bak, S.; Goossens, A. The TriForC database: A comprehensive up-to-date resource of plant triterpene biosynthesis. Nucleic Acids Res. 2018, 46, 586-594. [CrossRef]

18. Vincken, J.-P.; Heng, L.; de Groot, A.; Gruppen, H. Saponins, classification and occurrence in the plant kingdom. Phytochem. Rev. 2007, 68, 275-297. [CrossRef]

19. Arao, T.; Kinjo, J.; Nohara, T.; Isobe, R. Oleanene-type triterpene glycosides from Puerariae Radix. II. isolation of saponins and the application of tandem mass spectrometry to their structure determination. Chem. Pharm. Bull. 1995, 43, 1176-1179. [CrossRef]

20. Du, Y.E.; Lee, J.S.; Kim, H.M.; Ahn, J.-H.; Jung, I.H.; Ryu, J.H.; Choi, J.-H.; Jang, D.S. Chemical constituents of the roots of Codonopsis lanceolata. Arch. Pharm. Res. 2018, 41, 1082-1091. [CrossRef]

21. Myose, M.; Warashina, T.; Miyase, T. Triterpene saponins with hyaluronidase inhibitory activity from the seeds of Camellia sinensis Chem. Pharm. Bull. 2012, 60, 612-623. [CrossRef] 
22. Shimoyamada, M.; Harada, K.; Okubo, K. Saponin composition in developing soybean seed (Glycine max (L.) Merrill, cv. Mikuriyaao). Agric. Biol. Chem. 1991, 55, 1403-1405.

23. Shin, B.-K.; Kwon, S.W.; Park, J.H. Chemical diversity of ginseng saponins from Panax ginseng. J. Ginseng Res. 2015, 39, 287-298. [CrossRef] [PubMed]

24. Jeong, G.-T.; Park, D.-H.; Ryu, H.-W.; Hwang, B.; Woo, J.-C.; Kim, D.; Kim, S.-W. Production of antioxidant compounds by culture of Panax ginseng C.A. meyer hairy roots. In Twenty-Sixth Symposium on Biotechnology for Fuels and Chemicals; Humana Press: Totowa, NJ, USA, 2005; pp. 1147-1158.

25. Kim, B.-G.; Choi, S.-Y.; Kim, M.-R.; Suh, H.J.; Park, H.J. Changes of ginsenosides in Korean red ginseng (Panax ginseng) fermented by Lactobacillus plantarum M1. Process Biochem. 2010, 45, 1319-1324. [CrossRef]

26. Choi, Y.H.; Yoo, D.S.; Choi, C.W.; Cha, M.-R.; Kim, Y.S.; Lee, H.S.; Lee, K.R.; Ryu, S.Y. Platyconic acid A, a genuine triterpenoid saponin from the roots of Platycodon grandiflorum. Molecules 2008, 13, 2871-2879. [CrossRef]

27. Fu, W.-W.; Fu, J.-N.; Zhang, W.-M.; Sun, L.-X.; Pei, Y.-H.; Liu, P. Platycoside O, a new triterpenoid saponin from the roots of Platycodon grandiflorum. Molecules 2011, 16, 4371-4378. [CrossRef]

28. Fu, W.-W.; Shimizu, N.; Dou, D.-Q.; Takeda, T.; Fu, R.; Pei, Y.-H.; Chen, Y.-J. Five new triterpenoid saponins from the roots of Platycodon grandiflorum. Chem. Pharm. Bull. 2006, 54, 557-560. [CrossRef]

29. Fu, W.-W.; Shimizu, N.; Takeda, T.; Dou, D.-Q.; Chen, B.; Pei, Y.-H.; Chen, Y.-J. New A-ring lactone triterpenoid saponins from the roots of Platycodon grandiflorum. Chem. Pharm. Bull. 2006, 54, 1285-1287. [CrossRef]

30. Ji, S.; Wang, Q.; Qiao, X.; Guo, H.-C.; Yang, Y.-F.; Bo, T.; Xiang, C.; Guo, D.-A.; Ye, M. New triterpene saponins from the roots of Glycyrrhiza yunnanensis and their rapid screening by LC/MS/MS. J. Pharm. Biomed. Anal. 2014, 90, 15-26. [CrossRef]

31. Lee, D.Y.; Choi, B.-R.; Lee, J.W.; Um, Y.; Yoon, D.; Kim, H.-G.; Lee, Y.-S.; Kim, G.-S.; Lee, Y.-H.; Baek, N.-I. Simultaneous determination of various platycosides in four Platycodon grandiflorum cultivars by UPLC-QTOF/MS. Appl. Biol. Chem. 2019, 62, 1-10. [CrossRef]

32. Lee, J.W.; Ji, S.-H.; Kim, G.-S.; Song, K.-S.; Um, Y.; Kim, O.T.; Lee, Y.; Hong, C.P.; Shin, D.-H.; Kim, C.-K.; et al. Global profiling of various metabolites in Platycodon grandiflorum by UPLC-QTOF/MS. Int. J. Mol. Sci. 2015, 16, 26786-26796. [CrossRef]

33. Ouyang, H.; Zhou, M.; Guo, Y.; He, M.; Huang, H.; Ye, X.; Feng, Y.; Zhou, X.; Yang, S. Metabolites profiling of Pulsatilla saponin $\mathrm{D}$ in rat by ultra performance liquid chromatography-quadrupole time-of-flight mass spectrometry (UPLC/Q-TOF-MS/MS). Fitoterapia 2014, 96, 152-158. [CrossRef]

34. Wang, Q.; Xiao, B.-X.; Pan, R.-L.; Liu, X.-M.; Liao, Y.-H.; Feng, L.; Cao, F.-R.; Chang, Q. An LC-MS/MS method for simultaneous determination of three Polygala saponin hydrolysates in rat plasma and its application to a pharmacokinetic study. $J$. Ethnopharmacol. 2015, 169, 401-406. [CrossRef] [PubMed]

35. Xie, Y.; Pan, H.; Sun, H.; Li, D. A promising balanced Th1 and Th2 directing immunological adjuvant, saponins from the root of Platycodon grandiflorum. Vaccine 2008, 26, 3937-3945. [CrossRef] [PubMed]

36. Kim, Y.-K.; Sathasivam, R.; Kim, Y.B.; Kim, J.K.; Park, S.U. Transcriptomic analysis, cloning, characterization, and expression analysis of triterpene biosynthetic genes and triterpene accumulation in hairy roots of Platycodon grandiflorum exposed to methyl jasmonate. ACS Omega 2021, 6, 12820-12830. [CrossRef] [PubMed]

37. Ha, Y.W.; Na, Y.-C.; Ha, I.J.; Kim, D.-H.; Kim, Y.S. Liquid chromatography/mass spectrometry-based structural analysis of new platycoside metabolites transformed by human intestinal bacteria. J. Pharm. Biomed. Anal. 2010, 51, 202-209. [CrossRef] [PubMed]

38. Ma, C.-H.; Gao, Z.-J.; Zhang, J.-J.; Zhang, W.; Shao, J.-H.; Hai, M.-R.; Chen, J.-W.; Yang, S.-C.; Zhang, G.-H. Candidate genes involoved in the biosynthesis of triterpenoid saponins in Platycodon grandiflorum identified by transcriptome analysis. Front. Plant Sci. 2016, 7, 673. [CrossRef] [PubMed]

39. Nyakudya, E.; Jeong, J.H.; Lee, N.K.; Jeong, Y.S. Platycosides from the roots of Platycodon grandiflorum and their health benefits. Prev. Nutr. Food Sci. 2014, 19, 59-68. [CrossRef]

40. Su, X.; Liu, Y.; Han, L.; Wang, Z.; Cao, M.; Wu, L.; Jiang, W.; Meng, F.; Guo, X.; Yu, N.; et al. A candidate gene identified in converting platycoside E to platycodin D from Platycodon grandiflorus by transcriptome and main metabolites analysis. Sci. Rep. 2021, 11, 1-7. [CrossRef]

41. Mazol, I.; Micha, G.; Wojciech, C. Polyphenolic compounds from Platycodon grandiflorum A. DC. Acta Pol. Pharm. 2004, 61, 203-208.

42. Lu, H.; Ju, M.; Chu, S.; Xu, T.; Huang, Y.; Chan, Q.; Peng, H.; Gui, S. Quantitative and chemical fingerprint analysis for the quality evaluation of Platycodi Radix collected from various regions in China by HPLC coupled with chemometrics. Molecules 2018, 23, 1823. [CrossRef]

43. Yan, Y.Z.; Xue, J.C.; Wu, J.R.; Yoo, D.S.; Lee, S.Y.; Kim, Y.K.; Uddin, M.R.; Park, S.U. Variation of triterpenoid saponin content in Platycodon grandiflorum (Jacq.) A.D.C. Chem. Asian J. 2012, 24, 1268-1270.

44. Chang, Y.-J.; Kim, E.; Choi, Y.-S.; Jeon, K.-H.; Kim, Y.-B. Development process for decreasing bitterness of doraji (Platycodon grandiflorum). J. Korean Soc. Food. Sci. Nutr. 2015, 44, 1550-1557. [CrossRef]

45. Kim, S.-Y.; Lee, Y.-J.; Park, D.-S.; Kim, H.-R.; Cho, Y.S. Comparison of quality characteristics of Platycodon grandiflorum according to steaming and fermentation. Korean J. Food Preserv. 2015, 22, 851-858. [CrossRef]

46. Kim, S.J.; Arasu, M.V.; AL-Dhabi, N.A.; Yoo, D.S.; Park, M.H.; Shin, Y.S.; Lee, S.W. Quantitative determination of triterpenoidal saponins in Platycodi radix and its variation in different regions of Korean Peninsula: A herbal plant used as traditional medicine. Chem. Asian J. 2013, 25, 7093-7097. [CrossRef] 
47. Ling, Y.; Zheng, Y.; Liu, K.; Zhang, Q.; Lu, Y. Structure characterization and identification of triterpenoid saponins from the root of Platycodon grandiflorum by HPLC/ESI-QTOF-MS/MS. Chem. Asian J. 2014, 26, 6839-6844. [CrossRef]

48. Jeon, S.-H.; No, I.-R.; Kim, Y.-G.; Cho, Y.-S. Effects of organic fertilizer application on growth and medicinal ingredients of Platycodon grandiflorum Radix. Korea J. Org. Agric. 2016, 24, 511-524. [CrossRef]

49. Jeon, S.-H.; No, I.-R.; Kim, Y.-G.; Cho, Y.-S. Effect of mulching materials on the growth and medicinal ingredients in Platycodon grandiflorum Radix organic cultivation. Korea J. Org. Agric. 2017, 25, 187-201.

50. Jeon, S.-H.; No, I.-R.; Kim, Y.-G.; Chun, H.-S.; Cho, Y.-S. Effects of growth and medicinal ingredients of Platycodon grandiflorum Radix by organic and chemical fertilizers. Korea J. Org. Agric. 2017, 25, 403-417.

51. Jeon, S.-H.; No, I.-R.; Kim, Y.-G.; Shim, D.-B.; Cho, Y.-S. Effect of green manure crop on growth and medicinal ingredients of Platycodon grandiflorum Radix. Korea J. Org. Agric. 2018, 26, 233-243. [CrossRef]

52. Lee, B.J.; Jeon, S.H.; Lee, S.W.; Chun, H.S.; Cho, Y.S. Soil physico-chemistry and saponins content of Platycodon grandiflorum Radix cultured from different sites in Gyeongnam province. KJMCS 2014, 22, 463-468. [CrossRef]

53. Ha, I.J.; Ha, Y.W.; Kang, M.; Lee, J.; Park, D.; Kim, Y.S. Enzymatic transformation of platycosides and one-stop separation of platycodin D by high-speed countercurrent chromatography. J. Sep. Sci. 2010, 33, 1916-1922. [CrossRef] [PubMed]

54. Kil, T.-G.; Kang, S.-H.; Kim, T.-H.; Shin, K.-C.; Oh, D.-K. Enzymatic biotransformation of balloon flower root saponins into bioactive platycodin D by deglucosylation with Caldicellulosiruptor bescii $\beta$-glucosidase. Mol. Sci. 2019, 20, 3854. [CrossRef]

55. Zhou, W.; Liu, X.; Ye, L.; Feng, M.; Zhou, P.; Shi, X. The biotransformation of astragalosides by a novel acetyl estrase from Absidia corymbifera AS2. Process Biochem. 2014, 49, 1464-1471. [CrossRef]

56. Yoo, D.S.; Choi, Y.H.; Cha, M.R.; Lee, B.H.; Kim, S.-J.; Yon, G.H.; Hong, K.S.; Jang, Y.S.; Lee, H.S.; Kim, Y.S.; et al. HPLC-ELSD analysis of 18 platycosides from balloon flower roots (Platycodi Radix) sourced from various regions in Korea and geographical clustering of the cultivation areas. Food Chem. 2011, 129, 645-651. [CrossRef]

57. Lee, K.J.; Choi, J.H.; Kim, H.G.; Han, E.H.; Hwang, Y.P.; Lee, Y.C.; Chung, Y.C.; Jeong, H.G. Protective effect of saponins derived from the roots of Platycodon grandiflorum against carbon tetrachloride induced hepatotoxicity in mice. Food Chem. Toxicol. 2008, 46, 1778-1785. [CrossRef]

58. Xie, Y.; Deng, W.; Sun, H.; Li, D. Platycodin D2 is a potential less hemolytic saponin adjuvant eliciting Th1 and Th2 immune responses. Int. Immunopharmacol. 2008, 8, 1143-1150. [CrossRef]

59. Xie, Y.; Sun, H.-X.; Li, D. Platycodin D is a potent adjuvant of specific cellular and humoral immune responses against recombinant hepatitis B antigen. Vaccine 2009, 27, 757-764. [CrossRef]

60. Choi, J.H.; Yoo, K.-Y.; Park, O.K.; Lee, C.H.; Won, M.-H.; Hwang, I.K.; Ryu, S.Y.; Kim, Y.S.; Yi, J.-S.; Bae, Y.-S.; et al. Platycodin D and 2"-O-acetyl-polygalacin D2 isolated from Platycodon grandiflorum protect ischemia/reperfusion injury in the gerbil hippocampus. Brain Res. 2009, 1279, 197-208. [CrossRef] [PubMed]

61. Ryu, J.; Lee, H.J.; Park, S.H.; Kim, J.; Lee, D.; Lee, S.K.; Kim, Y.S.; Hong, J.-H.; Seok, J.H.; Lee, C.J. Effects of the root of Platycodon grandiflorum on airway mucin hypersecretion in vivo and platycodin D3 and deapi-platycodin on production and secretion of airway mucin in vitro. Phytomedicine 2014, 21, 529-533. [CrossRef] [PubMed]

62. Wang, C.; Levis, G.B.S.; Lee, E.B.; Levis, W.R.; Lee, D.W.; Kim, B.S.; Park, S.Y.; Park, E. Platycodin D and D3 isolated from the root of Platycodon grandiflorum modulate the production of nitric oxide and secretion of TNF- $\alpha$ in activated RAW 264.7 cells. Int. Immunopharmacol. 2004, 4, 1039-1049. [CrossRef]

63. Sun, H.; Chen, L.; Wang, J.; Wang, K.; Zhou, J. Structure-function relationship of the saponins from the roots of Platycodon grandiflorum for hemolytic and adjuvant activity. Int. Immunopharmacol. 2011, 11, 2047-2056. [CrossRef] [PubMed] 